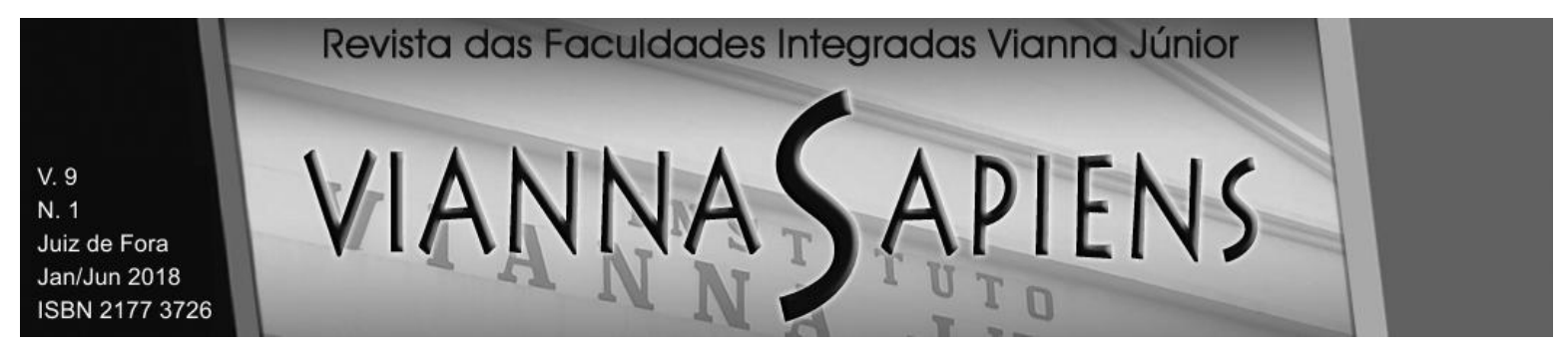

\title{
AVALIAÇÃO ECONÔMICO-FINANCEIRA DE PRODUÇÃO DE LEITE CAPRINO NA ZONA DA MATA MINEIRA \\ DOI: 10.31994/rvs.v9i1.269
}

\author{
Gustavo dos Santos Leal ${ }^{1}$ \\ Danilo de Oliveira Sampaio ${ }^{2}$ \\ Lupércio França Bessegato ${ }^{3}$
}

\section{RESUMO}

Este artigo procura analisar a viabilidade econômico-financeira de sistemas de produção de leite de cabra na Zona da Mata Mineira, levando em consideração a atual conjuntura econômica do Brasil. Foram estimados Fluxos de Caixa para dois sistemas de produção com raças de cabras distintas: a Saanen (Sistema 1) e a Toggenburg (Sistema 2). Considerando os distintos coeficientes técnicos de produção, e os coeficientes financeiros estimados, apenas o Sistema 1 foi classificado como viável, apresentando um VPL de R\$28.191,77, contra um VPL de $(\mathrm{R} \$ 21.608,89)$ do Sistema 2. A fim de se analisar os riscos inerentes ao negócio, foi aplicada uma Simulação de Monte Carlo, que mostrou que o Sistema 1 de Produção possui $66,40 \%$ de chances de apresentar um VPL positivo, contra $39,5 \%$ do Sistema 2.

\section{PALAVRAS-CHAVE: CAPRINOS. VIABILIDADE ECONÔMICO-FINANCEIRA. SIMULAÇÃO DE MONTE CARLO.}

\footnotetext{
${ }^{1}$ Mestre em Administração pelo PPGA/UFJF. e-mail: gsleal@outlook.com. https://orcid.org/00000002-8439-8743

${ }^{2}$ Doutor em Administração pelo CEPEAD/UFMG. e-mail: danilo.sampaio@ufjf.edu.br. https://orcid.org/0000-0002-5266-2327

${ }^{3}$ Doutor em Estatística pelo PPGEST/UFMG. e-mail: lupercio.bessegato@ufj.edu.br. https://orcid.org/0000-0002-5004-6790
} 


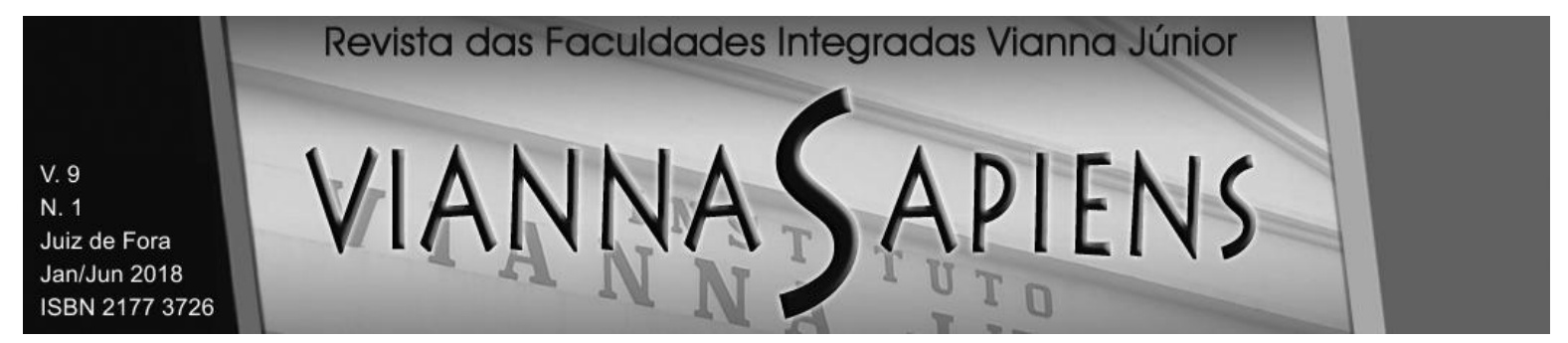

\section{INTRODUÇÃO}

A partir do momento em que a humanidade deixou de ser nômade passou a existir a necessidade de se desenvolver técnicas que viabilizassem o novo modelo de subsistência. Técnicas de cultivo fundamentadas na utilização de fertilizantes e defensivos, capacidades que proporcionam o acondicionamento de alimentos e a domesticação sistematizada de animais são exemplos de inovações que auxiliaram a viabilizar a transição para o modelo atual. Após a I Revolução Industrial, a produção dos bens e serviços adquiriu uma nova face, sendo que

o padrão de vida das massas formadas por cidadãos comuns começou a apresentar um crescimento contínuo e constante [...] nada remotamente parecido com este fenômeno econômico havia acontecido até então." (LUCAS, 2002 p.109-110).

Esta condição de melhoria contínua, entretanto, só é possível por meio da correta previsão das necessidades dos consumidores, que faz com que os investimentos sejam realizados de forma correta (HAYEK, 1932). Isto é, os estudos de viabilidade econômico-financeira são de suma importância para a criação de valor dos investimentos a serem realizados e, consequentemente, aumento da riqueza de uma sociedade.

Esses estudos mostram-se ainda mais importantes no segmento do agronegócio, em especial o mercado leiteiro que, por ser considerado competitivo, no qual os produtores de leite não possuem muitas condições de diferenciação de produtos ou de competição pelo preço, o controle dos custos é fundamental para a viabilidade do negócio.

O leite de cabra é o terceiro, oriundo de animal, mais consumido do mundo, atrás apenas do leite de vaca e do leite de búfala (FONSECA et al., 2011). Elas se alimentam de forma extensiva, de grãos, leguminosas, gramíneas e brotos, sendo facilmente adaptáveis a todo o tipo de clima, desde o árido até o frio de montanha (ARAÚJO FILHO, 2006). Como a diferença de adaptabilidade é bastante significativa em relação ao gado bovino, a região Nordeste do Brasil é a que concentra a maior parte desse tipo de animais (IBGE, 2008). 


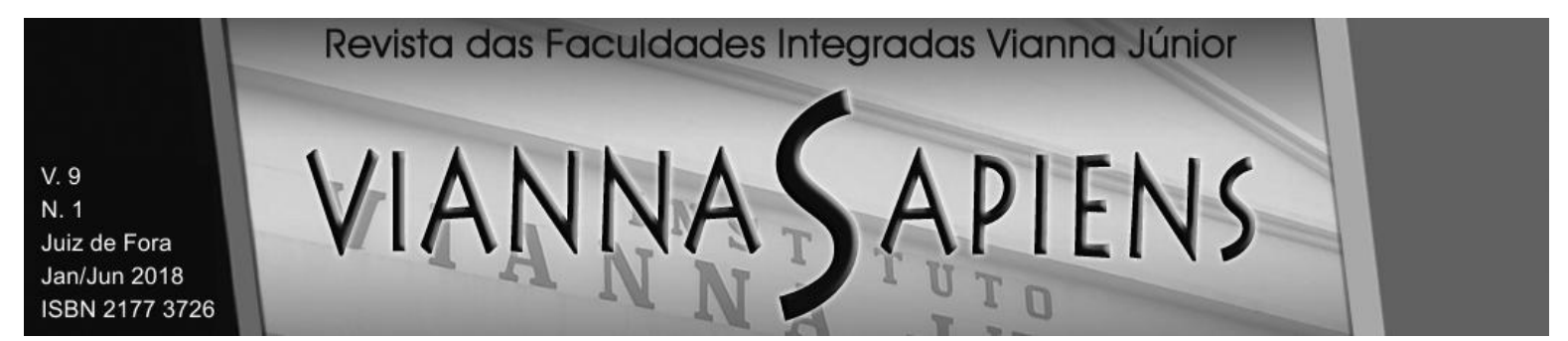

A produção mundial no ano de 2013 foi de, aproximadamente, 17.957.372 toneladas de leite (FAO, 2016). A Tabela 1 mostra a produção mundial e a divisão da produção por continentes.

Tabela 1. Produção mundial de leite de cabra entre os continentes.

\begin{tabular}{ccc}
\hline \hline Continente & Produção Total (Ton.) & $\%$ Mundo \\
\hline Produção Mundial & 17.957 .372 & $100 \%$ \\
Ásia & 10.653 .509 & $59,33 \%$ \\
África & 4.184 .887 & $23,30 \%$ \\
Europa & 2.526 .426 & $14,07 \%$ \\
América & 592.500 & $3,30 \%$ \\
Oceania & 50 & $0,00 \%$ \\
\hline \hline
\end{tabular}

Fonte: elaboração própria por meio de dados da FAO (2016).

Alguns trabalhos procuraram analisar a viabilidade do investimento em cabras leiteiras na região sudeste do Brasil, como Gonçalves (2005) e Deminicis et alli (2008), especificamente no estado no Rio de Janeiro. Os dois trabalhos demonstraram a viabilidade para a produção de caprinos leiteiros nas regiões analisadas. Entretanto, pela atual conjuntura econômica pós-crise mundial de 2008, existe a necessidade de reformulação dos cálculos, principalmente pelo contexto enfrentado nos últimos anos pelos criadores de gado leiteiro na em Minas Gerais, no qual, segundo dados de 2016 do Centro de Estudos Avançados em Economia Aplicada (CEPEA, 2016) os custos de produção de leite estão avançando de forma substancial sobre os preços de mercado. Assim, a produção de leite de cabra pode fornecer um complemento de renda aos produtores.

Segundo Carvalho e Hott (2009) a oferta de leite de cabra não acompanha o crescimento da demanda pelo produto, sendo que a oferta por $\mathrm{kg} / \mathrm{habitante}$ recuou de 2,05 nos anos 60 para 1,70 na década de 70. Posteriormente a média de disponibilidade do leite de cabra ficou em 2,12 kg/habitante entre 2000 e 2006. Assim, nota-se uma possível oportunidade de mercado a ser explorada pelos produtores rurais, a fim de gerar renda complementar sobre a produção principal da organização.

Conforme pode ser observado pela Tabela 1, a Ásia é o continente que concentra a maior produção de leite de cabra no mundo, com $59,33 \%$ do total, 


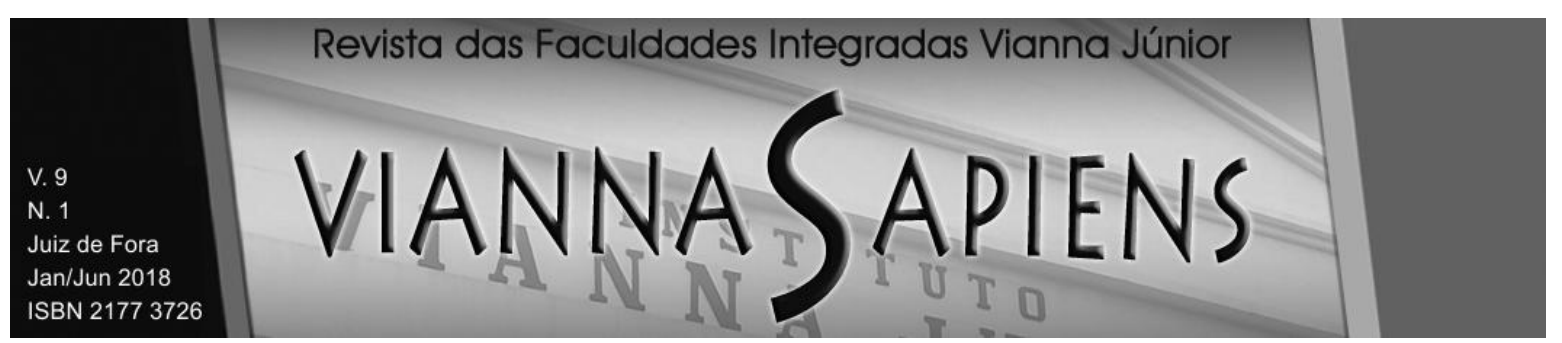

sendo seguia por África (23,30\%), Europa $(14,07 \%)$ e América $(3,30 \%)$. A Oceania possui produção irrisória desse tipo de leite.

O artigo tem como problema de pesquisa a questão: é viável a produção de leite advindo de caprinos na Zona da Mata Mineira, dada a atual conjuntura econômica do Brasil? O estudo possui como objetivo analisar a viabilidade econômico-financeira de sistemas de produção de caprinos leiteiros na Zona da Mata Mineira, considerando a conjuntura econômica do Brasil, tendo como objetivos específicos: 1) analisar a conjuntura econômica brasileira; 2) fixar os parâmetros de produção; 3) fixar os parâmetros financeiros para a análise; 4) gerar os resultados de análise de investimentos a fim de determinar a viabilidade econômico-financeira e; 5) criar modelos de Simulação de Monte Carlo para análise de risco.

Este trabalho está dividido em seis seções, além da introdução: 1) Metodologia; 2) Comparação de Conjunturas Econômicas; 3) Coeficientes Técnicos da Produção de Caprinos na Zona da Mata Mineira; 4) Fluxos de Caixa e Resultados; 5) Análise de Risco com aplicação de Simulação de Monte Carlo e comparação entre os modelos e; 6) Conclusão.

\section{ASPECTOS METODOLÓGICOS}

Esta pesquisa é do tipo descritiva, visto que foi observado um fenômeno durante um determinado tempo. A natureza do estudo foi quantitativa ao utilizar técnicas estatísticas bem como a simulação de Monte Carlo (MALHOTRA, 2012). Não foi realizado estudo amostral ao passo que foram pesquisados dados secundários.

A ideia básica de um projeto de investimento, de acordo com Ross et al. (2008), é a de se criar valor para os proprietários do capital. Levando em conta esta característica, pode-se ponderar sobre os indicadores para validação de projetos de forma mais clara, pois: 


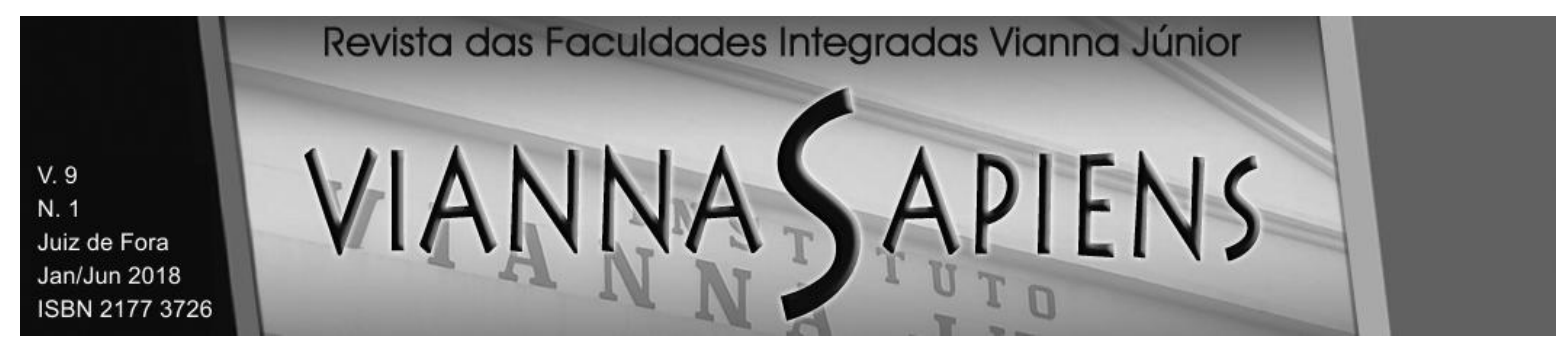

de um grande número de empresas rurais, como um projeto de expansão ou criação de atividades específicas em uma empresa já organizada. Seus objetivos têm de ser definidos claramente e sua duração e tamanho predeterminados. Existe uma data de início e outra de término das atividades que definem o projeto. É desta forma, uma unidade administrativa com fins específicos cujo papel na empresa não passa de guia na direção de seus objetivos de longo prazo. (NORONHA, 1987, p.26)

A análise de investimento é realizada por meio da apreciação de fluxos de caixa dos sistemas de produção a serem descritos. Para isso, como primeiro passo, estimam-se os desembolsos ou saídas necessárias a uma fazenda de produção caprina em concorrência perfeita. Em seguida, as saídas serão utilizadas na construção de fluxos de caixa que são a organização criteriosa do fluxo de entradas e saídas para cada sistema de produção.

O fluxo de caixa é divido em três partes (ROSS et al., 2008), e a fórmula para calculá-lo é dado pela Equação (I):

$$
F C=F C O-\triangle K C L-G K
$$

Para:

FC = Fluxo de Caixa; FCO ${ }^{i}=$ Fluxo de Caixa Operacional; $\triangle \mathrm{KCL}=$ Variação do Capital Circulante Líquido; ; GK = Gastos em Capital.

Com base nos fluxos de caixa, serão calculados os indicadores de viabilidade de projetos apresentados a seguir.

\subsection{Valor Presente Líquido (VPL)}

O VPL corresponde à soma algébrica dos fluxos de caixa em cada período descontados a uma taxa de desconto e é o indicador, em geral, preferido. O VPL é calculado segundo a Equação (II):

$$
V P L_{n}=F C_{0}+\frac{F C_{1}}{(1+r)^{1}}+\cdots+\frac{F C_{n}}{(1+r)^{n}}
$$

Para:

$V P L_{n}=$ Valor Presente Líquido de $n$ fluxos de caixa; $F C_{0}=$ Fluxo de Caixa do tempo $0 ; F C_{1}=$ Fluxo de Caixa do tempo $1 ; F C_{n}=$ Fluxo de Caixa do tempo $n ; r=$ Taxa de desconto. 


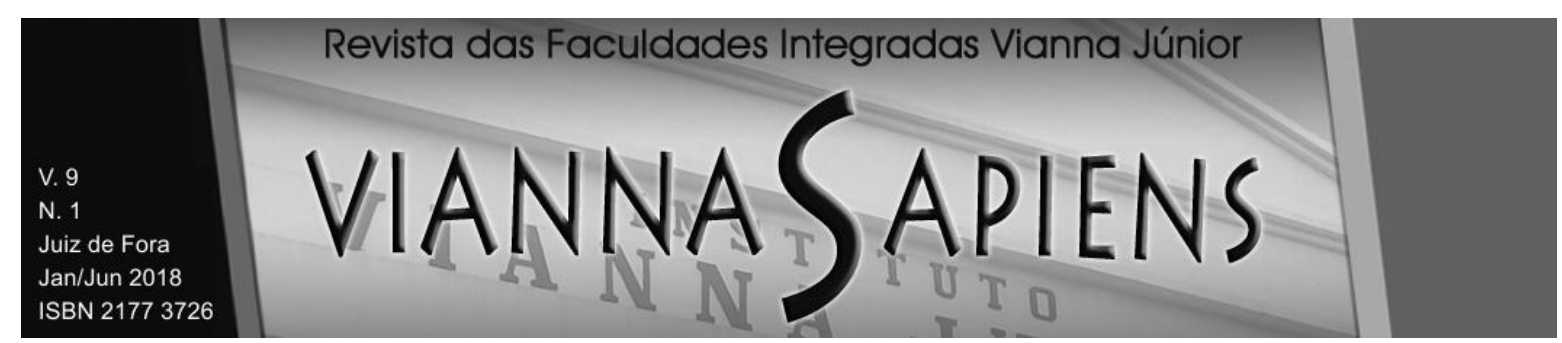

Um projeto de investimento é considerado viável financeiramente quando seu VPL for positivo. As vantagens do VPL, segundo Bruni et al. (1998) é que este método informa se o investimento agregará valor à empresa considerando o valor monetário no tempo, além do risco incluído na taxa de retorno ( $r$. Uma de suas desvantagens, de acordo com o mesmo autor, é a necessidade de se conhecer o valor da taxa de desconto $r$.

\subsection{Taxa Interna de Retorno (TIR)}

Outro indicador muito utilizado é a Taxa Interna de Retorno (TIR) que é a taxa que faz o VPL ser igual a zero (CONTADOR, 1988 e FARO, 1972). Ou seja, a TIR é o valor da taxa de desconto $r$ que faz com que a seguinte igualdade seja garantida:

Para:

$$
0=F C_{0}+\frac{F C_{1}}{(1+r)^{1}}+\cdots+\frac{F C_{n}}{(1+r)^{n}}
$$

$F C_{0}=$ Fluxo de Caixa do tempo $0 ; F C_{1}=$ Fluxo de Caixa do tempo $1 ; F C_{n}=$ Fluxo de Caixa do tempo $n ; r=$ Taxa de desconto.

Assim, compara-se a TIR à taxa de retorno utilizada no projeto. Se ela for maior, aprova-se o investimento. Apesar da grande aceitabilidade da TIR por sua facilidade de entendimento, ela apresenta problemas graves, tais como respostas múltiplas ao se trabalhar com fluxos de caixas não convencionais (que possuem mais de uma mudança de sinal), além de induzir a decisões imperfeitas quando analisados projetos mutuamente exclusivos.

\subsection{PAYBACK}

Outro indicador muito importante, mas que apresenta muitas desvantagens, é o payback. Segundo Ross et al. (2008). O payback é o tempo necessário para que um projeto gere fluxos de caixa capazes de cobrir o investimento inicial. Por este procedimento, um projeto é considerado viável se o seu payback for menor do que 


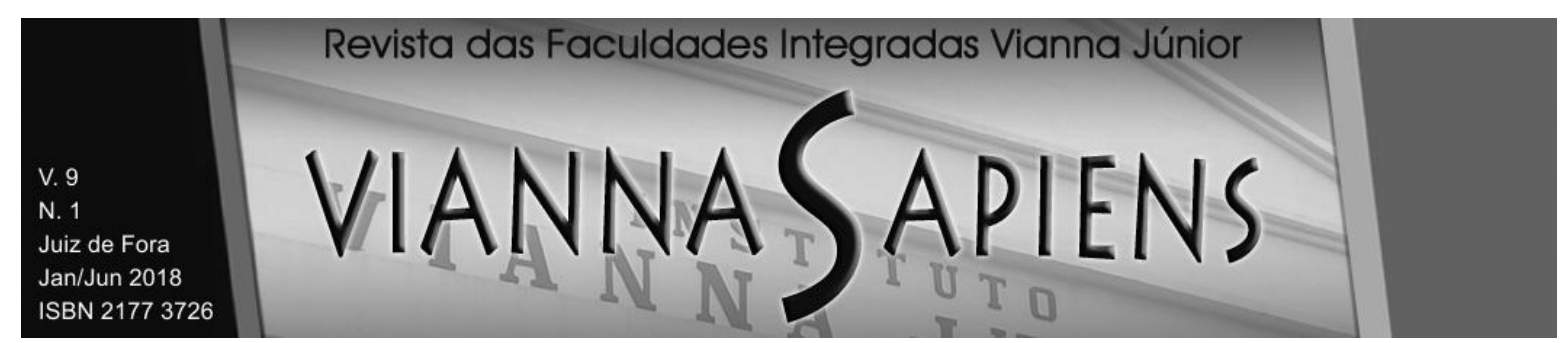

um determinado número de períodos de tempo previamente estabelecido pelo investidor.

O payback possui diversos problemas, pois não desconta os fluxos de caixa, ignorando o valor do dinheiro no tempo; além do número de anos escolhido para o "ponto de corte" é arbitrário, além de tender à liquidez (ASSAF NETO; LIMA, 2009).

\subsection{Custo do Capital (TAXA DE RETORNO)}

O custo do capital próprio, dado pelo Capital Asset Price Model (CAPM), será a taxa de retorno utilizada neste trabalho. Sua fórmula é mostrada na Equação (IV):

$$
C A P M=R_{f}+\beta\left(R_{m}-R_{f}\right)
$$

Para:

CAPM = Capital Asset Price Model; $R_{f}=$ Taxa livre de risco; $R_{m}=$ Taxa de retorno do mercado;

$\beta=$ Risco Sistêmico. É dado pela fórmula: $\frac{\operatorname{COV}(R m ; R a)}{\operatorname{VAR}(R m)}$, sendo $R_{a}=$ Retorno do ativo, ou de forma alternativa: $R_{a}=\alpha+\beta R_{m}$.

Segundo Assaf Neto e Lima (2009), o coeficiente beta é determinado por meio da identificação no mercado de organizações que podem ser classificadas de benchmarks, ou seja, organizações que atuam em atividades semelhantes que irão servir como guias para o cálculo do índice.

Como a análise de viabilidade proposta por este trabalho leva em consideração que a organização se instalaria no próprio terreno nacional, o mais comum seria considerar a taxa livre de risco como a Selic, que corresponde à taxa de juros básica da economia brasileira, e a taxa de retorno do mercado como o retorno do Índice da Bolsa de Valores de São Paulo (Ibovespa). Entretanto, nos últimos cinco anos, o retorno do lbovespa foi negativo, refletindo a crise econômica mundial de 2008, sendo, portanto, um problema para o cálculo do prêmio pelo risco. Considerou-se, então, como parâmetro o mercado norte-americano para o cálculo do CAPM e utilizou-se o Risco-Brasil como ajuste para "nacionalizar" a taxa encontrada. 


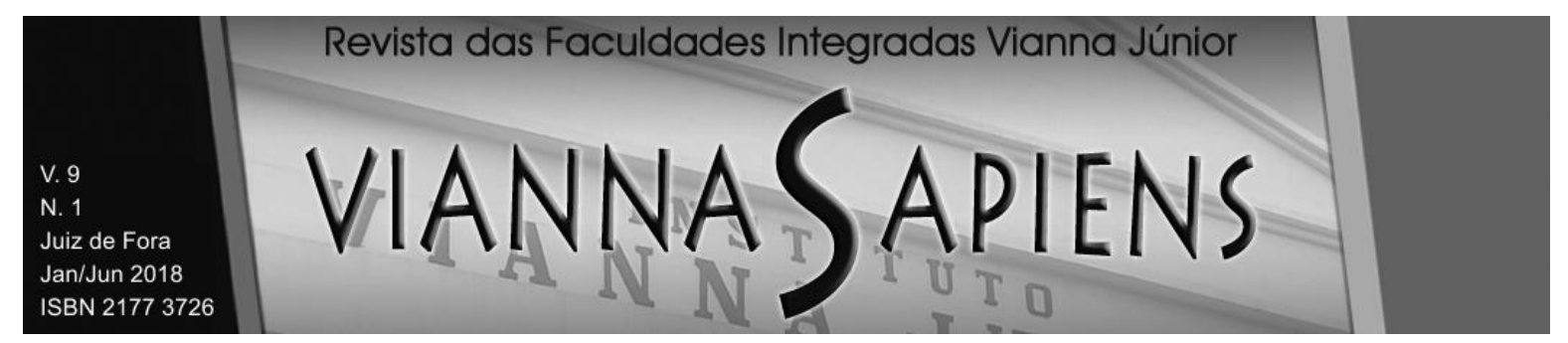

\subsection{Análise de Risco}

Em toda análise de engenharia econômica, deve-se levar em consideração o risco inerente ao investimento. Ao colocar o capital em uma atividade rentável, mas que ofereça riscos, é essencial que se realize uma análise de sensibilidade, que indica para qual determinada faixa de risco (alta), existe a necessidade de se refinar suas estimativas, enquanto para outras (baixas), as primeiras aproximações são o suficiente (FARO, 1972).

Como cada sistema de produção, que será estudado neste trabalho, possui riscos próprios, utiliza-se então a técnica de simulação de Monte Carlo (SMC). Essa prática "baseia-se no fato da frequência relativa de ocorrência de um indicador de avaliação financeira aproximar-se de sua probabilidade de ocorrência" (RESENDE FILHO et al., 2001). De acordo com Kiriakos (1997) as etapas a serem seguidas para a implementação da técnica são: a) construção do fluxo de caixa; b) elaboração de um modelo com as principais incertezas relativas às variáveis de análise do fluxo de caixa, utilizando-se de distribuições de probabilidade; c) determinação das relações entre as variáveis, já que em grande parte dos casos as variáveis aleatórias são dependentes; d) efetuar a simulação. Nesta etapa são gerados vários processos de amostragem, considerando-se as correlações entre as variáveis. Para cada amostragem, calculam-se os indicadores da análise econômico-financeira. Este procedimento deve ser repetido até que as flutuações dos valores das distribuições de saída sejam pequenas.

\section{COEFICIENTES TÉCNICOS DE PRODUÇÃO DE CAPRINOS}

Os coeficientes técnicos de produção correspondem a valores numéricos que correspondem às quantidades de insumos gastos a fim de que se produza uma determinada quantidade de leite em um dado período de tempo (EMBRAPA, 2003).

Estas informações possuem elevada importância para 0 aferimento dos custos de produção, principalmente os relativos à alimentação do rebanho, e 


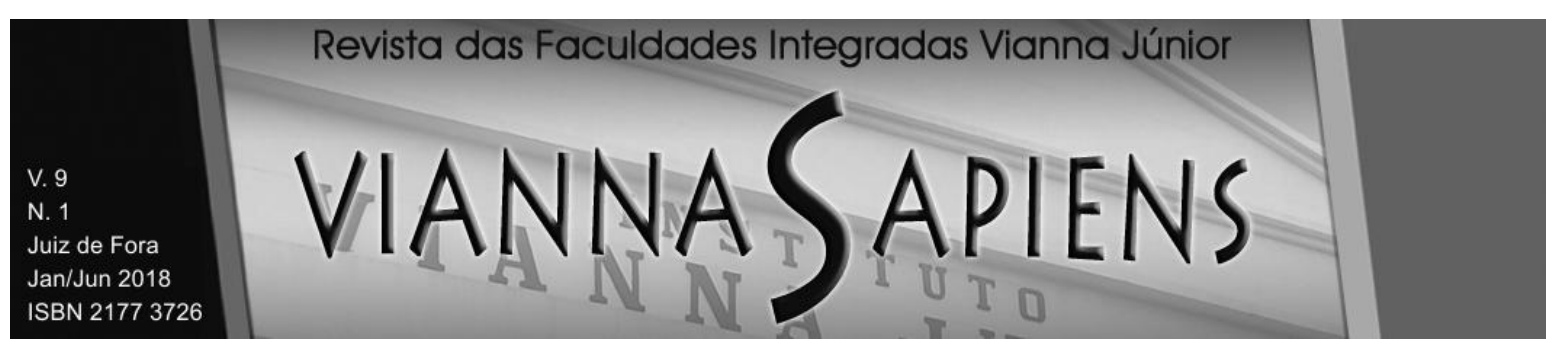

também para a projeção das receitas, pois fornece dados diretamente relacionados, como prolificidade, produtividade e período de gestação. Além disso, houve o cuidado de fornecer ao possível investidor informações relevantes para que este possa iniciar a atividade caprino-leiteira.

\subsection{Raças Consideradas}

Foram consideradas para este estudo duas raças de caprinos: Saanen e Toggenburg. A raça Saanen é originária da suíça e é muito explorada em regiões onde existe caprinocultura bem desenvolvida por conta da sua alta produção leiteira e persistência de lactação (CAPRITEC, 2008). Apresenta peso que varia de $75 \mathrm{~kg}$ a $90 \mathrm{~kg}$ para as fêmeas e entre $80 \mathrm{~kg}$ a $120 \mathrm{~kg}$ para os machos (CAPRITEC, 2008).

Já a raça Toggenburg também é originária da Suíça e é predominante neste país e na Inglaterra. O peso médio para machos adultos encontra-se, em torno, de $70 \mathrm{~kg}$ e para a fêmea em torno de 50kg (EMBRAPA, [s.d.] )

Para este trabalho, serão considerados dois sistemas de produção. $O$ Sistema I e o Sistema II, com 97 animais cada, 85 cabras e 12 reprodutores, sendo o primeiro com animais da raça Saanen e o segundo com animais da raça Toggenburg.

\subsection{INSTALAÇÕES}

O tamanho das instalações deve ser previamente dimensionado de modo a que sirvam unicamente para a instalação adequada dos animais e sem superdimensionamento (Tabela 2). 


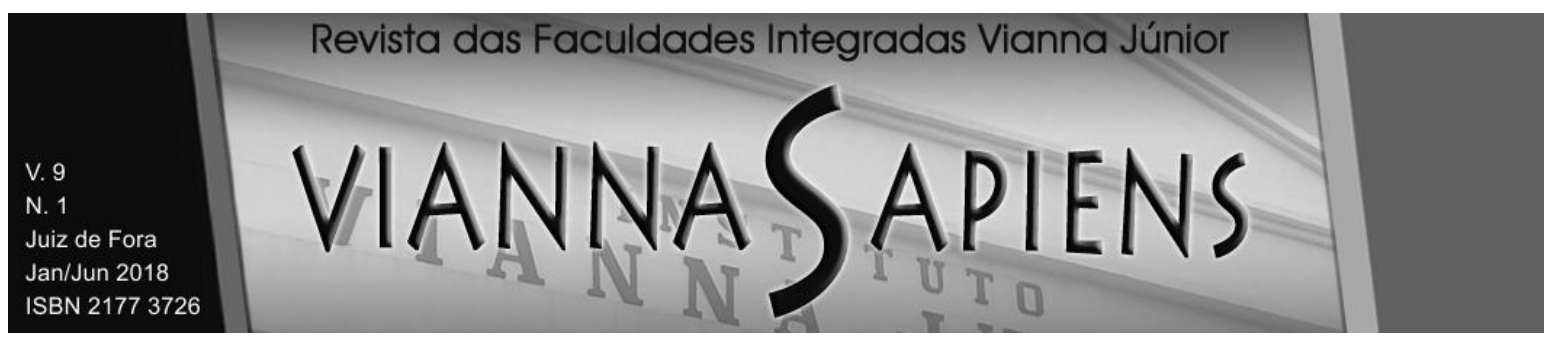

Tabela 2. Área coberta e descoberta de exercício de caprinos leiteiros por cabeça/m².

\begin{tabular}{c|c}
\hline \hline Categoria Animal & Área Coberta $\left(\mathrm{m}^{2}\right)$ \\
\hline Matrizes & 1,0 \\
\hline Animais Jovens & 0,8 \\
\hline Crias & 0,5 \\
\hline Reprodutores & 3,0 \\
\hline \hline
\end{tabular}

Fonte: LEAL (2010).

Além disso, para Deminicis et al. (2008), há a necessidade de $532 \mathrm{~m}^{2}$ de área externa para que cada animal tenha alimentação e sobreviva de forma adequada. Atualizando o valor do $\mathrm{m}^{2}$ de instalações adequadas para cabras de Deminicis et al. (2008), chega-se ao valor de $\mathrm{R} \$ 52,80 / \mathrm{m}^{2}$.

\subsection{Descrição dos Sistemas}

Conforme exposto, este artigo estudou dois sistemas de produção que são descritos conforme a Tabela 3.

Tabela 3. Descrição dos Sistemas de Produção Avaliados.

\begin{tabular}{lc|c}
\hline \hline & Sistema 1 & Sistema 2 \\
\hline Raça & Saanen & Toggenburg \\
\hline Quantidade & 97 & 97 \\
\hline Fêmeas & 85 & 85 \\
\hline Fertilidade & $85 \%$ & $85 \%$ \\
\hline Prolificidade & 1,50 & 1,75 \\
\hline Produção esterco & $600 \mathrm{~kg} / \mathrm{ano}$ & $600 \mathrm{~kg} / \mathrm{ano}$ \\
\hline
\end{tabular}

- Continuação -

\begin{tabular}{lc|c}
\hline Perda de esterco & $50 \%$ & $50 \%$ \\
\hline Produção leite média & $2,37 \mathrm{~kg} / \mathrm{dia}$ & $2,18 \mathrm{~kg} / \mathrm{dia}$ \\
\hline Lactação média & $283 \mathrm{dias}$ & $275 \mathrm{dias}$ \\
\hline Mortalidade & $3 \%$ & $3 \%$ \\
\hline \hline
\end{tabular}

Fonte: elaboração própria. 


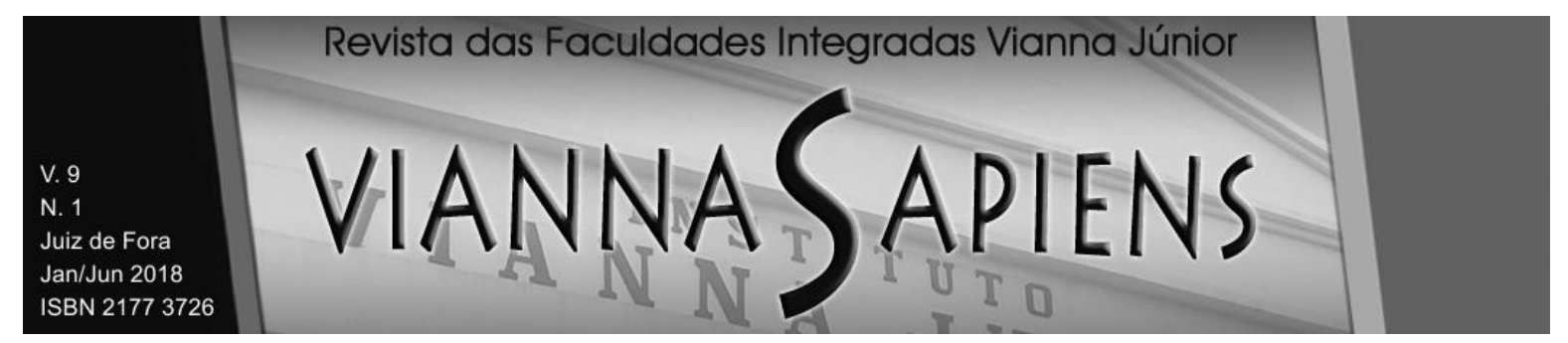

Conforme descrito a raça das cabras analisada para o Sistema 1 é a Saanen que possui a maior produtividade leiteira entre as raças de cabras analisadas (THOLON, 2001). A taxa de fertilidade considerada para este sistema foi de $85 \%$, a prolificidade de 1,5/fêmea (GONÇALVES, 2005) e a taxa de mortalidade foi de $3 \%$ (DEMINICIS et al., 2008). A produção média de leite das cabras Saanen considerada no Sistema 1 foi de 669,20 kg/ano por animal, com desvio de $97 \mathrm{~kg}$, sendo o período de lactação de 281 dias (THOLON, 2001).

A raça caprina analisada para o Sistema 2 foi a Toggenburg. Os parâmetros utilizados foram os mesmos para o Sistema 1 apenas diferenciando-se a produção de leite, a duração do período de lactação e a prolificidade. O período de lactação considerado para este sistema foi de 275 dias (FONSECA; BRUSCHI, 2009). A produção média de leite por animal foi de $2,18 \mathrm{~kg} /$ dia, sendo o mínimo de 1,82 kg/dia e o máximo de 2,54 kg/dia. A prolificidade média considerada foi de 1,50 e 1,75, respectivamente (LEAL, 2010 e ESPECHIT, 1998), a taxa de fertilidade de 85\% e a mortalidade de $3 \%$ é igual valor ao sistema anterior. Importante ressaltar que este trabalho considera os dois sistemas de produção como semi-intensivos, ou seja, a principal parte da alimentação se dará em pastagens, sendo aplicada uma mistura como complemento alimentar. Outro fator essencial é que como o leite pode ser concebido como um bem que se insere em mercados competitivos (VARIAN, 2006), toda produção será vendida.

O preço do esterco em 2002 foi de $R \$ 1,00$ para cada $30 \mathrm{~kg}$ (EMBRAPA, 2002), dessa forma, atualizou-se esse preço para o ano de 2016, utilizando-se o Índice de Preços ao Consumidor Amplo (IPCA), chegando ao valor de $\mathrm{R} \$ 2,48$. $A$ perda de esterco de $50 \%$ corresponde ao fato de que a caprinocultura é uma atividade complementar a outras práticas agropecuárias tradicionais, como a bovinocultura leiteira (FONSECA; BRUSCHI, 2009), sendo provável a utilização desta produção de esterco para outra atividade. Além disso, o preço médio do leite de cabra direto ao produtor de $M G$ considerado foi de $R \$ 2,50$, com desvio de $\mathrm{R} \$ 0,50$ (CAPRILEITE, 2016). 


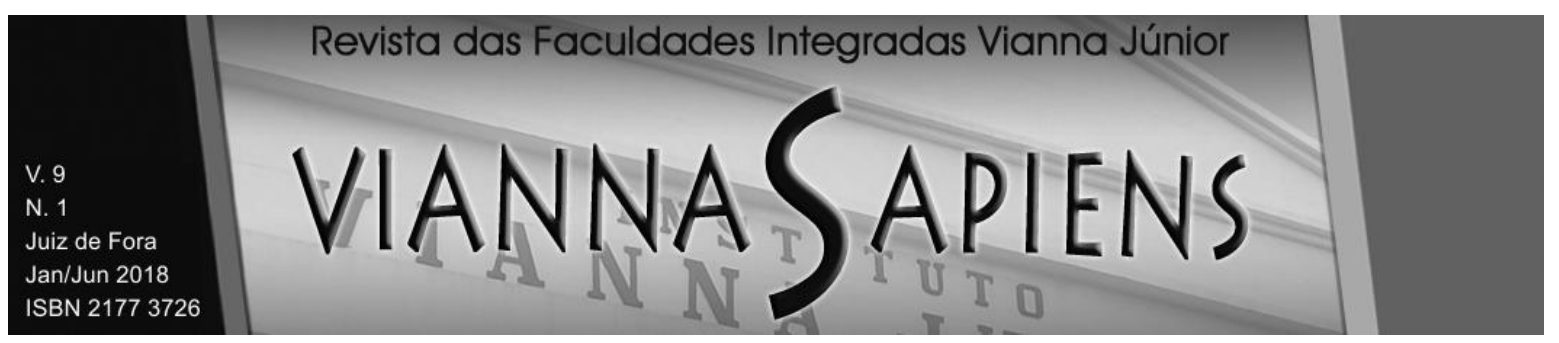

\section{FLUXO DE CAIXA ESTIMADO E RESULTADOS}

Para analisar a viabilidade econômico-financeira de um empreendimento, devem-se levar em conta quatro aspectos: determinação dos gastos em capital líquido; a previsão de receitas e dos custos de $t_{1}$ a $t_{n}$, sendo $n$ o tempo total de previsão; a determinação da taxa de retorno, ou da taxa mínima de atratividade; e a geração e análise dos resultados.

Os investimentos necessários para a criação de caprinos e a produção de leite advinda desses animais são: terreno, instalações físicas, animais, esterqueira e capital de giro inicial. Quanto à aquisição de um terreno, ou seu respectivo custo de oportunidade, o preço do hectare considerado foi de $R \$ 9.374,77$ (FAEMG, 2016), considerando um desvio-padrão de $\mathrm{R} \$ 2.673,99$. Conforme a Tabela 1, necessitamse para os sistemas propostos de 5 hectares de terra e $130 \mathrm{~m}^{2}$ de área coberta. Já em relação ao preço médio de compra dos animais, foi considerado o valor de $R \$ 1.750,00$ para cada reprodutor com desvio de $R \$ 250,00$ e de $R \$ 1.650,00$ para as matrizes, com desvio de $\mathrm{R} \$ 350,00$ (CAPRILEITE, 2016). De acordo com Deminicis et al. (2008), a esterqueira apresentava um custo total em 2006 de $\mathrm{R} \$ 69,00 / \mathrm{m}^{3}$. Assim, atualizando o valor pelo Índice de Preços ao Consumidor Amplo, chegandose a $\mathrm{R} \$ 118,55 / \mathrm{m}^{3}$, totalizando $\mathrm{R} \$ 8.441,01$.

Considerando tratamento semi-intensivo, a aplicação de uma mistura como é essencial para a manutenção dos animais, e é proposta segundo a Tabela 4.

Tabela 4. Composição de Mistura para alimentação caprina.

\begin{tabular}{l|c|c}
\hline \multicolumn{1}{c|}{ Composição } & Preço/Kg & Total \\
\hline $27 \mathrm{~kg}$ de milho & $\mathrm{R} \$ 0,64$ & $\mathrm{R} \$ 17,23$ \\
\hline $16 \mathrm{~kg}$ de farinha de ossos calcinada & $\mathrm{R} \$ 2,68$ & $\mathrm{R} \$ 42,88$ \\
\hline $10 \mathrm{~kg}$ de ureia pecuária & $\mathrm{R} \$ 2,77$ & $\mathrm{R} \$ 27,70$ \\
\hline $15 \mathrm{~kg}$ de farelo de algodão ou de soja & $\mathrm{R} \$ 1,37$ & $\mathrm{R} \$ 20,55$ \\
\hline $30 \mathrm{~kg}$ de sal mineral & $\mathrm{R} \$ 8,59$ & $\mathrm{R} \$ 257,70$ \\
\hline $1,3 \mathrm{~kg}$ de flor de enxofre & $\mathrm{R} \$ 5,85$ & $\mathrm{R} \$ 7,60$ \\
\hline $0,6 \mathrm{~kg}$ de sulfato de zinco & $\mathrm{R} \$ 7,91$ & $\mathrm{R} \$ 4,75$ \\
\hline $0,08 \mathrm{~kg}$ de sulfato de cobre & $\mathrm{R} \$ 12,37$ & $\mathrm{R} \$ 0,99$ \\
\hline $0,02 \mathrm{~kg}$ de sulfato de cobalto & $\mathrm{R} \$ 275,00$ & $\mathrm{R} \$ 5,50$ \\
\hline Total (100 kg) & \multicolumn{2}{|c}{$\mathrm{R} \$ 384,90$} \\
\hline \hline
\end{tabular}

Fonte: elaboração própria com dados da Embrapa (2002) e IEA (2015). 


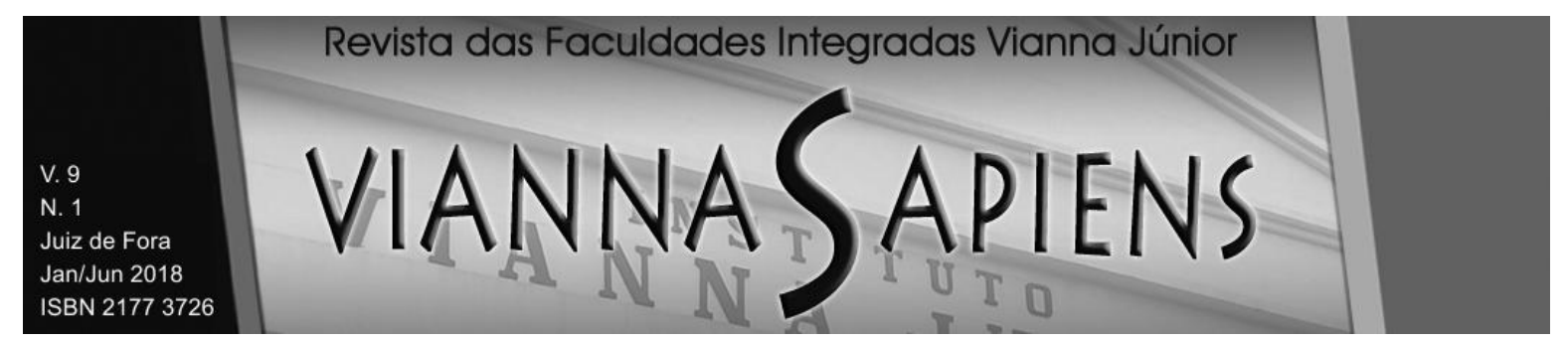

As receitas consideradas para os dois sistemas foram: receita com leite, vendas de animais nascidos e receita com esterco, com os coeficientes técnicos já apresentados. Quanto à venda de animais nascidos, foram consideradas a taxa de fertilidade e a taxa de mortalidade cmo $85 \%$ e $3 \%$ respectivamente para os dois sistemas de produção (DEMINICIS et al., 2008), com a taxa de fertilidade variando 3\% (GONÇALVES, 2005). Há 163 cabritos a serem vendidos em uma média de 2 em 2 anos por conta do período de fertilidade médio de 394 dias para a raça Saanen e 445 dias para a raça Toggenburg (SOARES FILHO et al., 2001). O preço de venda de cada cabrito é, em média, de $R \$ 300,00$. Foram desconsiderados o valor dos animais no final do período, pois a taxa de depreciação de cabras é de $20 \%$ a.a.. As Demonstrações de Resultado do Exercício estimadas são apresentadas na Tabela 5.

Tabela 5. Fluxos de Caixa Estimado para o Sistema de Produção 1.

\begin{tabular}{|c|c|c|c|c|c|c|}
\hline Sistema de Produção 1 & Ano 0 & Ano 1 & Ano 2 & Ano 3 & Ano 4 & Ano 5 \\
\hline 1. Investimentos & $(288.733,19)$ & & & & & $95.531,51$ \\
\hline 1.1. Terra e Instalações & $(92.676,87)$ & & & & & $66.401,50$ \\
\hline 1.2. Animais Adultos & $(161.250,00)$ & & & & & \\
\hline 1.3. Esterqueira & $(8.441,01)$ & & & & & $7.596,91$ \\
\hline 1.4. Bebedouro (3 unds) & $(11.800,00)$ & & & & & $6.967,78$ \\
\hline 1.5. Capital de Giro & $(14.565,32)$ & & & & & $14.565,32$ \\
\hline 2. Custos Operacionais & & $(98.568,24)$ & $(100.861,55)$ & $(98.568,24)$ & $(100.861,55)$ & $(98.568,24)$ \\
\hline 2.1. Concentrado Alimentar & & $(46.185,36)$ & $(46.185,36)$ & $(46.185,36)$ & $(46.185,36)$ & $(46.185,36)$ \\
\hline 2.2. Vitaminas, vacinas e remédios & & $(3.915,42)$ & $(3.915,42)$ & $(3.915,42)$ & $(3.915,42)$ & $(3.915,42)$ \\
\hline 2.3. Mão de Obra & & $(39.000,00)$ & $(39.000,00)$ & $(39.000,00)$ & $(39.000,00)$ & $(39.000,00)$ \\
\hline 2.4. Energia e Combustível & & $(2.913,06)$ & $(3.563,31)$ & $(2.913,06)$ & $(3.563,31)$ & $(2.913,06)$ \\
\hline 2.5. Impostos (4,5\% da RT) & & $(6.554,39)$ & $(8.017,45)$ & $(6.554,39)$ & $(8.017,45)$ & $(6.554,39)$ \\
\hline 3. Receitas & & $145.653,16$ & $178.165,66$ & $145.653,16$ & $178.165,66$ & $145.653,16$ \\
\hline 3.1. Leite & & $142.525,88$ & $142.525,88$ & $142.525,88$ & $142.525,88$ & $142.525,88$ \\
\hline 3.2. Vendas de animais nascidos & & & $32.512,50$ & & $32.512,50$ & \\
\hline 3.3. Esterco & & $3.127,28$ & $3.127,28$ & $3.127,28$ & $3.127,28$ & $3.127,28$ \\
\hline 4. Fluxo de Caixa & $(288.733,19)$ & $47.084,92$ & $77.484,10$ & $47.084,92$ & $77.484,10$ & $142.616,43$ \\
\hline 5. Fluxo de Caixa Descontado & & $44.340,26$ & $68.714,02$ & $39.321,58$ & $60.936,59$ & $105.621,28$ \\
\hline
\end{tabular}

O investimento estimado necessário para o sistema é de $\mathrm{R} \$ 288.733,19$, sendo $32 \%$ em terras e instalações, $56 \%$ em animais e $5 \%$ referente ao capital de giro, que foi calculado como $10 \%$ da Receita Total do primeiro ano (DEMINICIS et al., 2008). No Ano 5, os investimentos em terras, capital de giro, bebedouros e 


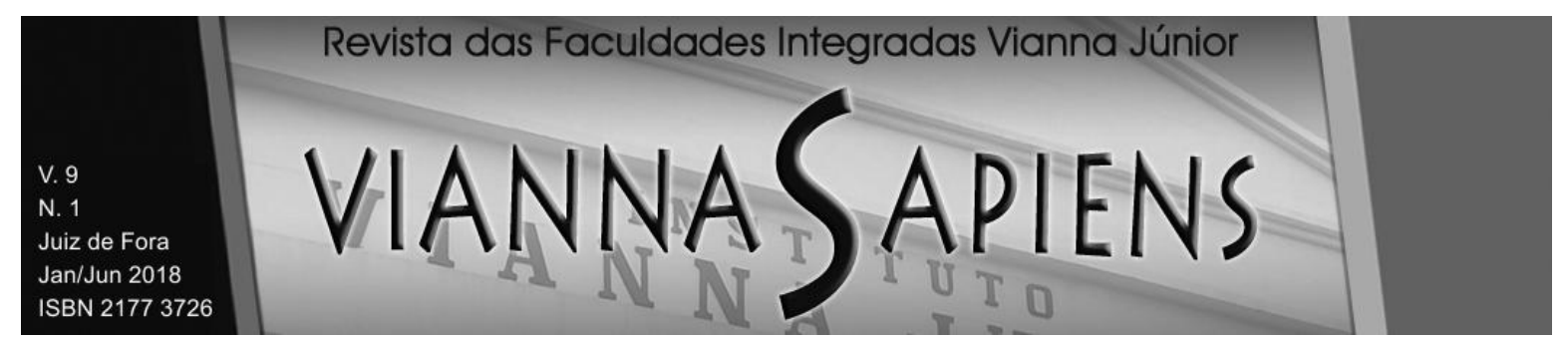

capital de giro retornam como positivos ao Fluxo de Caixa, já que se considerou que o projeto possui vida útil deste período, sendo que a terra não sofre depreciação. Já em relação aos custos operacionais, o valor do concentrado alimentar, que serve como complemento nutricional às cabras, corresponde a $47 \%$ do total, sendo que os impostos abarcam $4,5 \%$ da Receita Total, correspondendo a $6,65 \%$ do total dos custos operacionais.

A Tabela 6 mostra o Fluxo de Caixa estimado para o Sistema de Produção 2, que possui animais da raça Toggenburg como ativos. Observa-se que há uma diferença em todos os aspectos agregados estimados aos dois sistemas, como investimentos - que diferem em $R \$ 1.513,21$ - custos, pois no Sistema 2 o Concentrado, que é o custo que possui maior porcentagem em relação ao custo total, é dado por menos tempo por causa do menor período de lactação, e a receita, pelo mesmo motivo de menor tempo de lactação e pela menor prolificidade apresentada por esta raça em relação à Saanen, diminuindo as receitas bianuais com vendas de filhotes.

Tabela 6. Fluxos de Caixa Estimado para o Sistema de Produção 2.

\begin{tabular}{|c|c|c|c|c|c|c|}
\hline Sistema de Produção 2 & Ano 0 & Ano 1 & Ano 2 & Ano 3 & Ano 4 & Ano 5 \\
\hline 1. Investimentos & $(287.219,98)$ & & & & & $94.018,29$ \\
\hline 1.1. Terra e Instalações & $(92.676,87)$ & & & & & $66.401,50$ \\
\hline 1.2. Animais Adultos & $(161.250,00)$ & & & & & \\
\hline 1.3. Esterqueira & $(8.441,01)$ & & & & & $7.596,91$ \\
\hline 1.4. Bebedouro (3 unds) & $(11.800,00)$ & & & & & $6.967,78$ \\
\hline 1.5. Capital de Giro & $(13.052,10)$ & & & & & $13.052,10$ \\
\hline 2. Custos Operacionais & & $(97.584,65)$ & $(100.064,27)$ & $(97.584,65)$ & $(100.064,27)$ & $(97.584,65)$ \\
\hline 2.1. Concentrado Alimentar & & $(46.185,36)$ & $(46.185,36)$ & $(46.185,36)$ & $(46.185,36)$ & $(46.185,36)$ \\
\hline 2.2. Vitaminas, vacinas e remédios & & $(3.915,42)$ & $(3.915,42)$ & $(3.915,42)$ & $(3.915,42)$ & $(3.915,42)$ \\
\hline 2.3. Mão de Obra & & $(39.000,00)$ & $(39.000,00)$ & $(39.000,00)$ & $(39.000,00)$ & $(39.000,00)$ \\
\hline 2.4. Energia e Combustível & & $(2.610,42)$ & $(3.373,38)$ & $(2.610,42)$ & $(3.373,38)$ & $(2.610,42)$ \\
\hline 2.5. Impostos (4,5\% da RT) & & $(5.873,45)$ & $(7.590,11)$ & $(5.873,45)$ & $(7.590,11)$ & $(5.873,45)$ \\
\hline 3. Receitas & & $130.521,03$ & $168.669,03$ & $130.521,03$ & $168.669,03$ & $130.521,03$ \\
\hline 3.1. Leite & & $127.393,75$ & $127.393,75$ & $127.393,75$ & $127.393,75$ & $127.393,75$ \\
\hline 3.2. Vendas de animais nascidos & & & $38.148,00$ & & $38.148,00$ & \\
\hline 3.3. Esterco & & $3.127,28$ & $3.127,28$ & $3.127,28$ & $3.127,28$ & $3.127,28$ \\
\hline 4. Fluxo de Caixa & $(287.219,98)$ & $32.936,38$ & $68.604,76$ & $32.936,38$ & $68.604,76$ & $126.954,67$ \\
\hline 5. Fluxo de Caixa Descontado & & $31.016,46$ & $60.839,69$ & $27.505,85$ & $53.953,52$ & $94.022,24$ \\
\hline
\end{tabular}

Fonte: elaboração própria. 


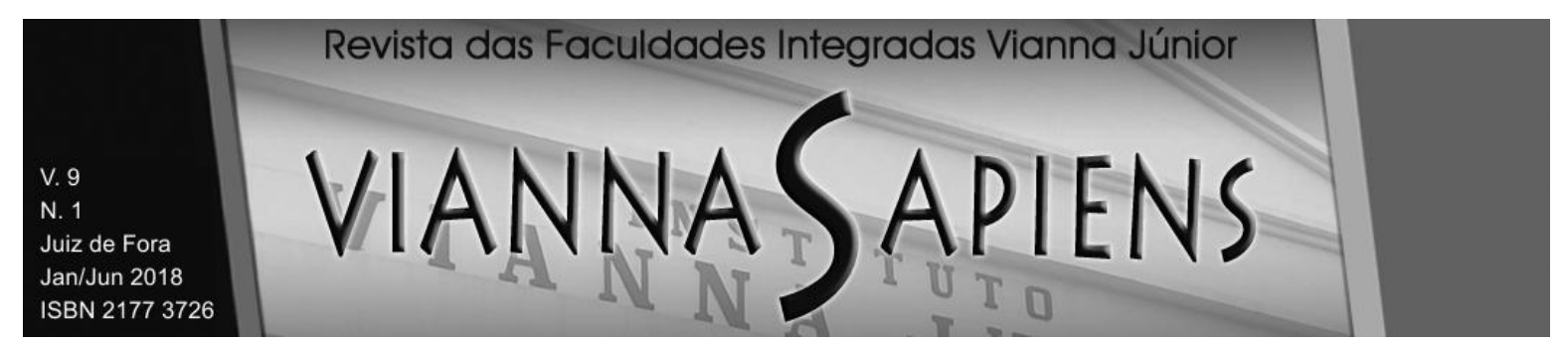

Dado os Fluxos de Caixa estimados, é necessário o cálculo da Taxa de Retorno, que neste trabalho se dará pela determinação do Capital Asset Price Model (CAPM). Conforme manifestado, o CAPM possui três fatores a serem calculados: a taxa livre de risco, a taxa de retorno do mercado e o índice beta, que representa 0 risco sistêmico de determinada carteira de ativos. Apesar de comum a utilização da Taxa Selic e do retorno do índice lbovespa para representar a taxa livre de risco e a taxa de retorno do mercado respectivamente, este trabalho considerará os títulos do Tesouro dos Estados Unidos representando o primeiro parâmetro e o retorno da Bolsa de Valores de Nova lorque, representando o segundo parâmetro, porque nos últimos cinco anos o retorno médio da Taxa Selic encontra-se acima do retorno médio do lbovespa, proporcionando um prêmio pelo risco negativo, o que gera problemas no cálculo do CAPM. Já o beta foi calculado possuindo como parâmetro as empresas de alimentação listadas na mesma bolsa de valores.

Neste contexto, a fim de ajustar a taxa calculada para a realidade brasileira, adicionou-se o prêmio pelo risco, que é, basicamente, a diferença entre o retorno dos títulos públicos brasileiros e dos títulos públicos americanos. Importante observar que, como os fluxos de caixa foram estimados de forma "real", a taxa de retorno encontrada foi deflacionada pelo índice de inflação de preços oficial do país, que é o IPCA. Assim, os parâmetros utilizados para o cálculo do CAPM são apresentados na Tabela 7.

Tabela 7. Critérios para o cálculo da Taxa de Retorno (CAPM).

\begin{tabular}{cccc}
\hline \hline Variável & Parâmetro & Variável & Parâmetro \\
\hline Rf (T-Bonds - 5 anos) & $0,21 \%$ & IPCA & $6,87 \%$ \\
\hline Rm (NYSE - 5 anos) & $6,44 \%$ & CAPM & $13,70 \%$ \\
\hline$\beta$ (Setor Alimentício NYSE - 5 anos) & 0,44 & CAPM Real & $6,39 \%$ \\
\hline SELIC & $10,75 \%$ & & \\
\hline \hline
\end{tabular}

Fonte: elaboração própria.

A taxa de retorno aplicada para a especificação dos indicadores de análise de viabilidade econômico-financeira foi de $6,39 \%$ a.a.. A Tabela 8 mostra o Valor 


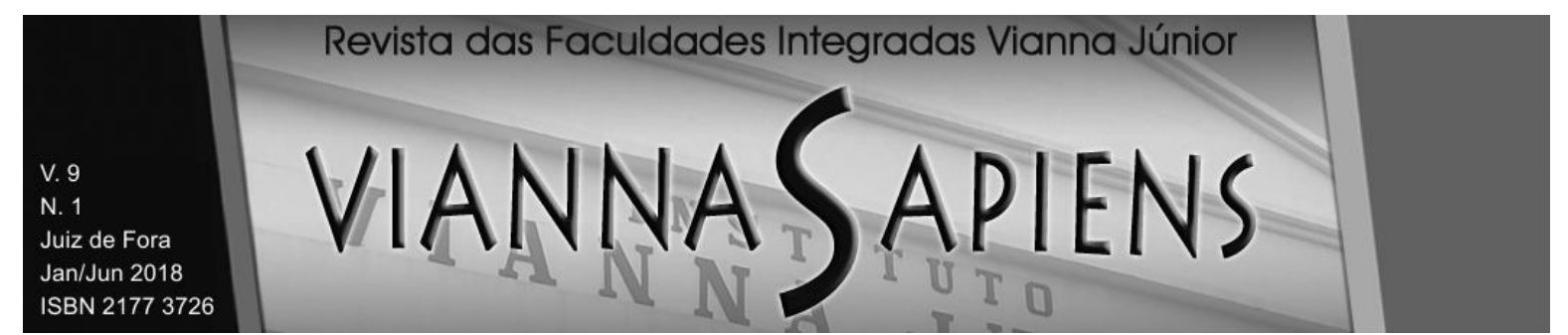

Presente Líquido, a Taxa Interna de Retorno, o Payback e o Payback descontado estimados para os dois sistemas de produção propostos por este trabalho.

Tabela 8. Indicadores de viabilidade econômico-financeira dos sistemas de produção propostos.

\begin{tabular}{ccc|ccc}
\hline & Sistema 1 & Sistema 2 & & Sistema 1 & Sistema 2 \\
\hline VPL & $\mathrm{R} \$ 28.191,77$ & $(\mathrm{R} \$ 21.608,89)$ & Payback & 4,33 anos & - \\
\hline TIR & $9,41 \%$ & $4,02 \%$ & $\begin{array}{c}\text { Payback } \\
\text { Descontado }\end{array}$ & 4,75 anos & - \\
\hline
\end{tabular}

Fonte: elaboração própria.

Dado que apenas o Sistema 1 de Produção apresentou o Valor Presente Líquido positivo, aprova-se apenas este sistema de produção, ficando clara sua superioridade em valores médios.

\section{ANÁLISE DE RISCO APLICADA: SIMULAÇÃO DE MONTE CARLO}

Este artigo propõe para quantificação do risco, conforme exposto, a utilização da técnica de Simulação de Monte Carlo. O Quadro 1 resume as variáveis que serviram de inputs aos dois modelos propostos e qual a distribuição proposta para sua utilização, dada pelo menor Bayesian Information Criterion (BIC) que mede o quão ajustado está determinada distribuição de probabilidade aos dados - ou triangular para variáveis que não possuem uma série disponível.

Quadro 1. Variáveis e Distribuições de Probabilidade (continua).

\begin{tabular}{|c|c|c|c|}
\hline Variável & $\begin{array}{c}\text { Distribuição de } \\
\text { Probabilidade }\end{array}$ & Variável & $\begin{array}{c}\text { Distribuição de } \\
\text { Probabilidade }\end{array}$ \\
\hline Custo da Terra (Hectares) & Triangular & Concentrado Alimentar & Triangular \\
\hline Preço das Matrizes & Triangular & Custo da Mão de obra & Triangular \\
\hline Preço dos Reprodutores & Triangular & T-Bond & Normal Inversa \\
\hline Produção de Leite & Triangular & Bolsa de Nova York & Triangular \\
\hline Preço & Triangular & Taxa Selic & Uniforme \\
\hline Período de Lactação & Triangular & IPCA & Triangular \\
\hline Fertilidade & Triangular & Preço do Milho & Triangular \\
\hline
\end{tabular}

Fonte: elaboração própria. 


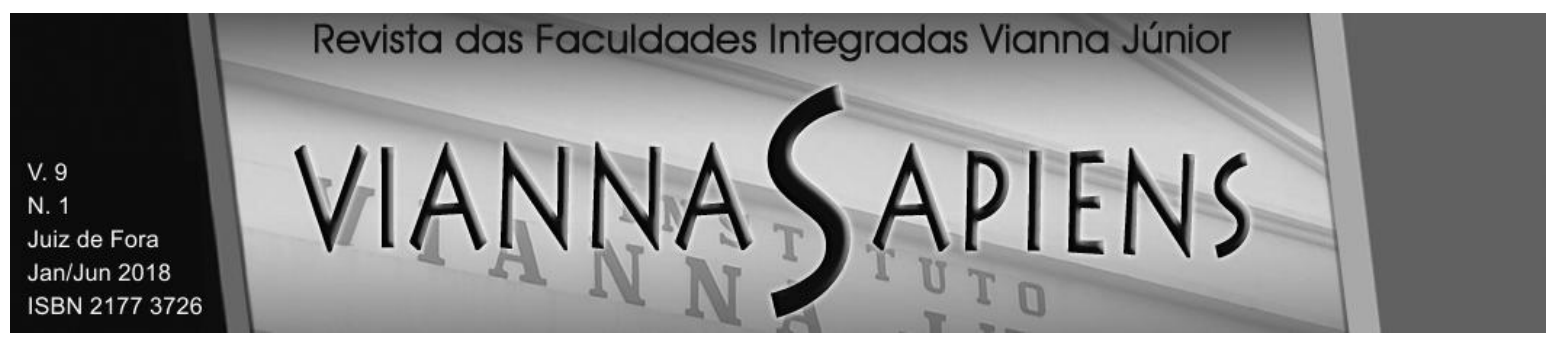

Os dados propostos para os Fluxos de Caixa dos sistemas foram tabulados no software Excel, no qual foram criadas, também, as distribuições de probabilidades propostas e realizadas 10.000 iterações, no software Excel, entre as variáveis dos modelos propostos, tendo como outputs os critérios de seleção de investimentos utilizados neste trabalho: Valor Presente Líquido e Taxa Interna de Retorno.

Conforme pode ser observado pela Figura 2, há $66,40 \%$ de chances do VPL ser positivo no primeiro sistema proposto, contra $33,60 \%$ de probabilidade dele se apresentar como um valor negativo. Nota-se que, para o Sistema 2 de produção, há apenas $39,50 \%$ de chances do VPL ser positivo, contra $60,50 \%$ dele ser negativo. Quanto a escalas intermediárias, existe $51 \%$ e $33,70 \%$ de chances do VPL estar entre $R \$ 0,00$ e $R \$ 100.000,00$, respectivamente para os Sistemas 1 e 2 .

A Tabela 9 mostra algumas estatísticas descritivas oriundas dos histogramas do Valor Presente Líquidos dos dois sistemas. Analisando-se os valores de medida central, nota-se que o Sistema 1 de produção é superior, inclusive apresentando menor desvio padrão da distribuição de probabilidade do VPL, com o Sistema 1 apresentando um mínimo de ( $R \$ 167.836,87)$ e máximo de $R \$ 279,008,87$, contra um mínimo de $(\mathrm{R} \$ 217.233,85)$ e máximo de $\mathrm{R} \$ 256.457,14$ do Sistema 2. As medidas de curtose aproximam-se da distribuição gaussiana nos dois sistemas.

Tabela 9. Estatísticas descritivas das distribuições dos VPLs para o Sistema 1 e o Sistema 2.

\begin{tabular}{ccc}
\hline \hline & Sistema 1 & Sistema 2 \\
\hline Média & $\mathrm{R} \$ 31.093,10$ & $(\mathrm{R} \$ 16.368,94)$ \\
Mediana & $\mathrm{R} \$ 28.331,62$ & $(\mathrm{R} \$ 20.413,62)$ \\
Moda & $\mathrm{R} \$ 17.383,91$ & $(\mathrm{R} \$ 43.468,87)$ \\
Desvio-Padrão & $\mathrm{R} \$ 65.832,70$ & $\mathrm{R} \$ 70.976,86$ \\
Assimetria & 0,22 & 0,27 \\
Curtose & 2,85 & 2,85 \\
\hline & - Continua - & \\
\hline Mínimo & - continuação - & $(\mathrm{R} \$ 217.233,85)$ \\
Máximo & $(\mathrm{R} \$ 167.836,87)$ & $\mathrm{R} \$ 256.457,14$ \\
\hline \hline
\end{tabular}

Fonte: elaboração própria.

Desta maneira, observa-se claramente a superioridade do Sistema 1 de produção de leite de cabras caprinos proposto para a Zona da Mata Mineira, já que 


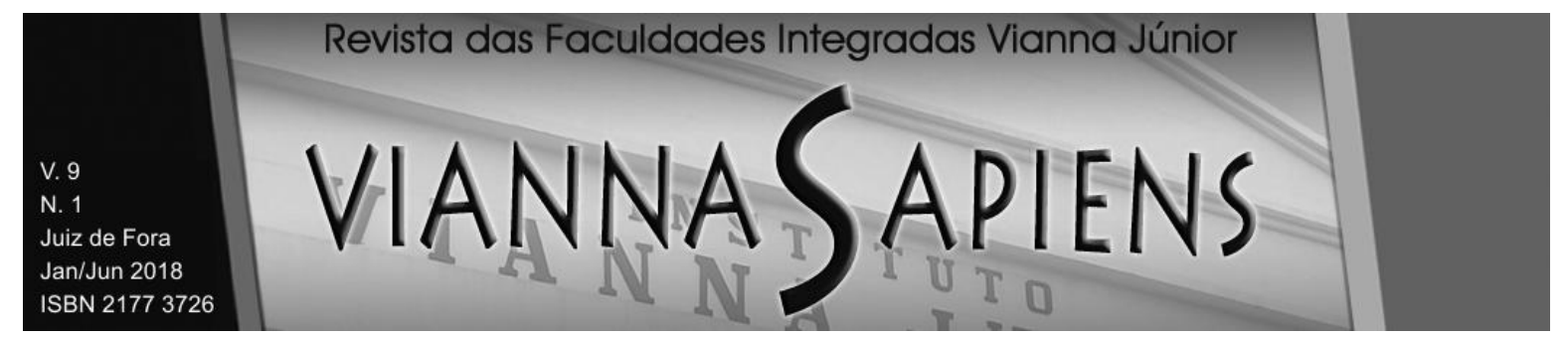

todas as estatísticas de medida central são superiores às do Sistema 2, apresentando inclusive menor amplitude entre os modelos e menor variabilidade dos resultados em torno da média. Este fato fica melhor visualizado pela Figura 2 que mostra os gráficos dos VPLs sobrepostos. O Sistema 1 é representado pela curva cinza e o Sistema 2 pela curva preta.

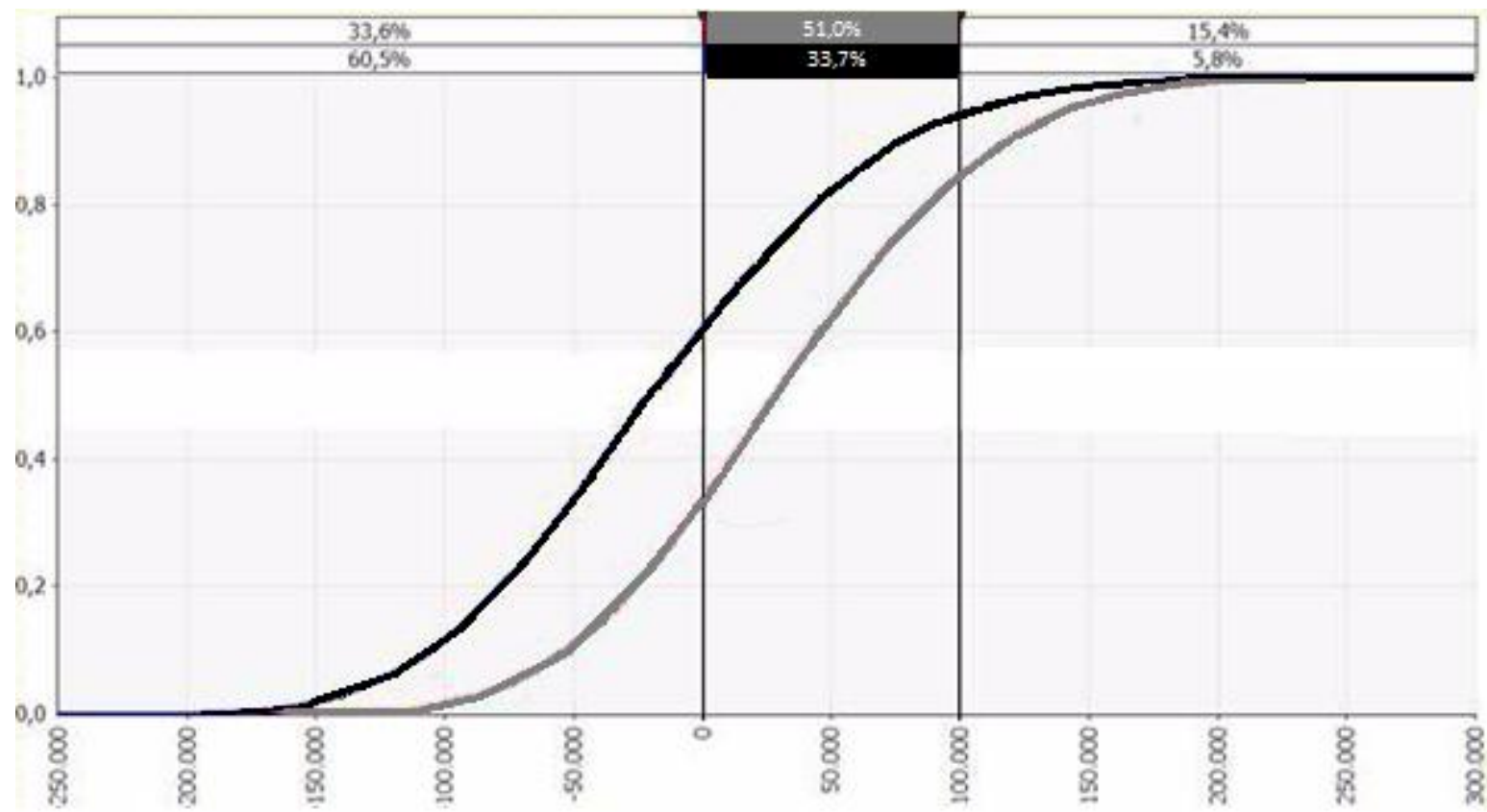

Figura 1. Gráfico de distribuição de probabilidade acumulada dos VPLs sobrepostos para dos Sistemas 1 e 2 de criação de caprinos na Zona da Mata Mineira. Fonte: elaboração própria.

A Figura 2 ratifica que o Sistema de Produção 1 é superior, em resultados, ao Sistema de Produção 2, já que o gráfico acumulado do VPL posiciona-se em toda sua totalidade à direita do gráfico referente ao segundo sistema.

\section{CONCLUSÃO}

Este artigo propôs o estudo de viabilidade econômico-financeira da criação de sistemas de caprinos leiteiros na Zona da Mata de Minas Gerais. Foram apresentados dois modelos de produção: um composto por cabras da raça Saanen e outro por cabras da raça Toggenburg. Apesar de já existirem estudos que abrangem sistemas de produção de caprinos leiteiros, este artigo propõe um novo 


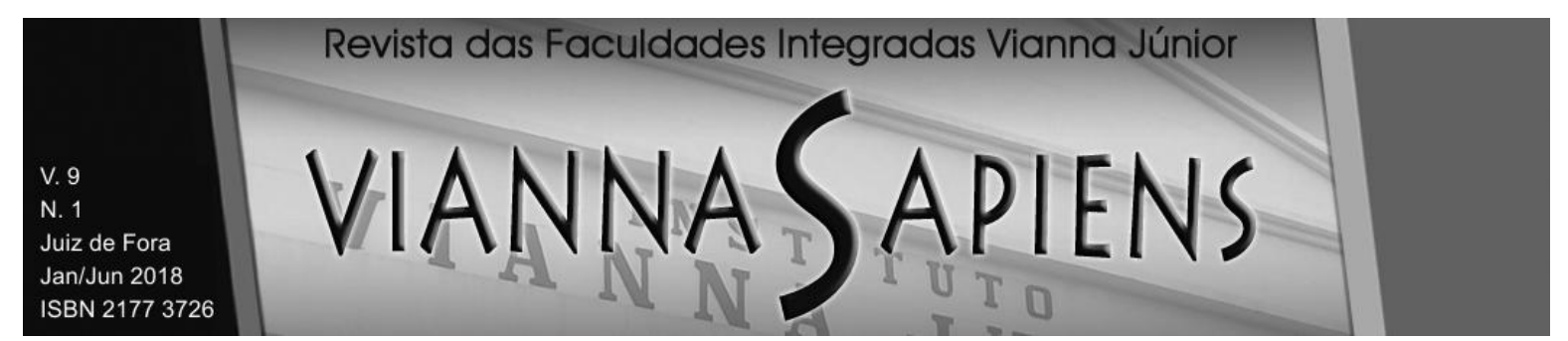

estudo, justamente pela mudança de conjuntura econômica enfrentada pelos diversos países e, principalmente, pelo Brasil. A fim de gerar os resultados propostos, foram levantados, de forma secundária, coeficientes técnicos de produção de caprinos leiteiros, tais como: produção de esterco, mortalidade, vacinas e remédios, produção de leite, prolificidade, alimentação, instalações necessárias, mão de obra etc.

Foram estimados os Fluxos de Caixa para os sistemas propostos e gerados resultados que refletem a esperança um cenário realista sobre o futuro, mostrando que o Sistema 1 de Produção seria viável economicamente, com um VPL de R\$ 28.191,77, enquanto que o Sistema 2 de Produção apresenta um VPL de (R\$ $21.608,89)$, não sendo recomendável a aprovação do projeto.

Para a análise de risco, propôs-se a aplicação da técnica de Simulação de Monte Carlo. O Sistema 1 de Produção possui $66,40 \%$ de chances de apresentar um VPL positivo, contra $33,60 \%$ de ser negativo, enquanto que o Sistema 2 apresenta apenas $39,50 \%$ de chances de o VPL ser positivo, contra, portanto, $60,50 \%$ de se encontrar abaixo de zero. Recomenda-se, para novos estudos, o estudo de viabilidade econômico-financeira de produtos oriundos do leite de cabra, como queijos e doces, além de analisar a viabilidade de criação de ovinos.

\section{AGRADECIMENTO}

Os autores agradecem à CAPES, ao CNPq e à FAPEMIG pelo apoio concedido ao projeto. 


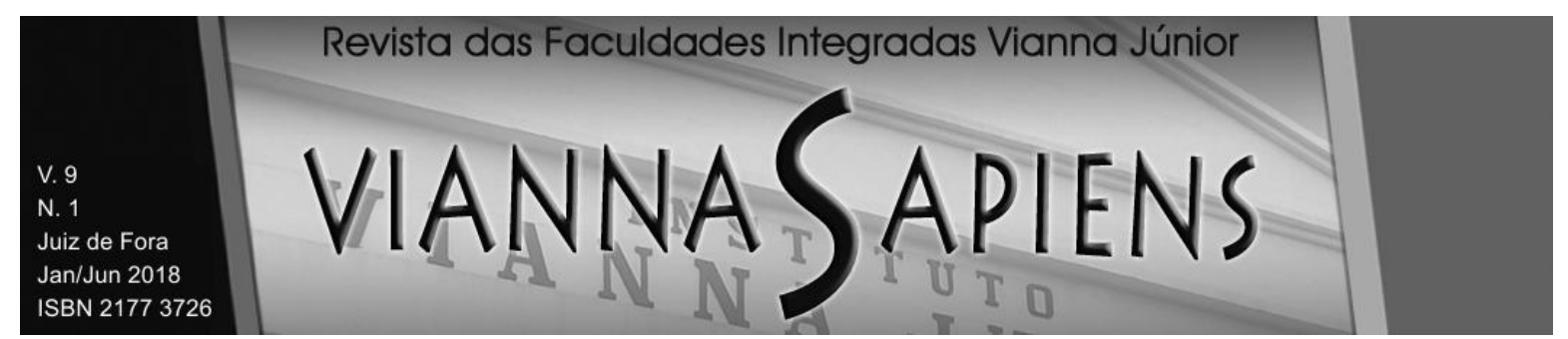

\title{
ECONOMIC AND FINANCIAL VIABILITY OF SYSTEMS OF GOAT MILK PRODUCTION AT THE "ZONA DA MATA” OF MINAS GERAIS
}

\begin{abstract}
This paper analyzes the economic and financial viability of systems of goat milk production at the "Zona da Mata" region in the state of Minas Gerais, Brazil, taking into account the current economic conjuncture of Brazil. Cash Flows was estimated for two production systems with distinct goat breeds: the Saanen (System 1) and the Toggenburg (System 2). Considering the different technical production coefficients and the estimate financial coefficients, only System 1 is viable, exhibiting a NPV of $\mathrm{R} \$ 28,191.77$ against a NPV of System 2 of $(\mathrm{R} \$ 21,608.89)$. In order to analyze the risks to the business, a Monte Carlo Simulation was applied, indicating that the System 1 of Production presents $66.40 \%$ of chance of has a positive NPV against $39.5 \%$ chance on System 2.
\end{abstract}

KEYWORDS: GOATS. ECONOMIC AND FINANCIAL VIABILITY. MONTE CARLO SIMULATION.

\section{REFERÊNCIAS}

ARAÚJO FILHO, J. A. Aspectos zooecológicos e agropecuários do caprino e do ovino nas regiões semi-áridas. Embrapa Caprinos. Documentos, 2006.

ASSAF NETO, A.; LIMA, F. G. Curso de administração financeira. Atlas, 2009.

BANCO CENTRAL DO BRASIL. Indicadores Econômicos Consolidados, 2016.

Disponível em: < http://www.bcb.gov.br/pec/Indeco/Port/indeco.asp>. Acesso em: 25/07/2016.

BLANCHARD, Olivier. Macroeconomia. Pearson Prentice Hall. 5ª edição. 2011. 


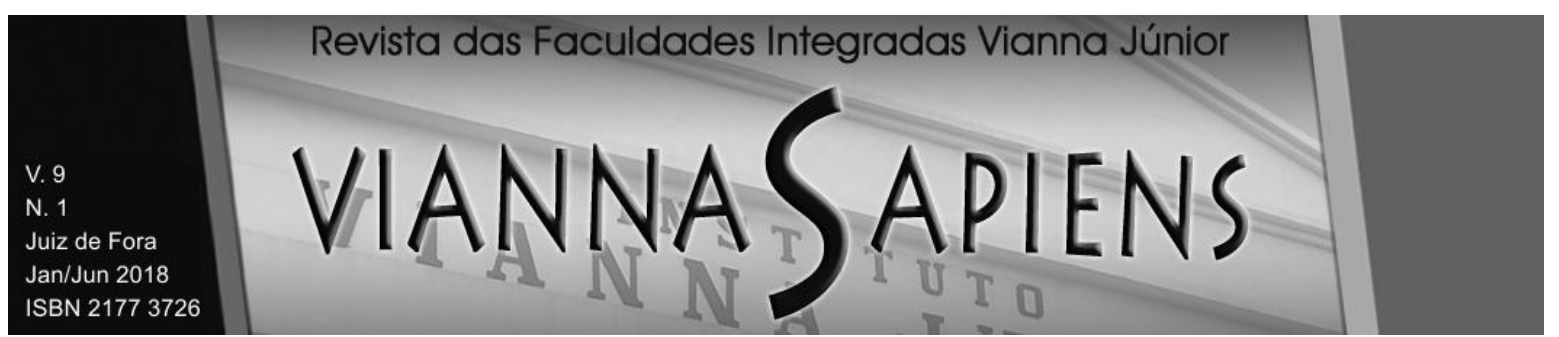

BRUNI, A. L.; FAMÁ, R.; SIQUEIRA, J. O. Análise do risco na avaliação de projetos de investimento: uma aplicação do método de Monte Carlo. Caderno de pesquisas em Administração, v. 1, n. 6, p. 62-74, 1998.

CAPRITEC. A raça Saanen, 2008. Disponível em: <http://www.capritec.com.br/csa/Rebanho/Saanen/Reb-Saa.htm>. Acesso em: 30/07/2016.

CAPRILEITE. Cotação de caprinos, 2016. Disponível em: <http://www.caprileite.com.br/conteudo/57-II-confira-a-cotacao-dos-caprinos>. Acesso em: 25/07/2016.

CARVALHO, G. R.; HOTT, M. C. O mercado de leite de pequenos ruminantes, in FONSECA, J.F.; BRUSCHI, J.H. Produção de caprinos na região da Mata

Atlântica. Sobral: Embrapa Caprinos; Juiz de Fora: Embrapa Gado de Leite, 2009.

CENTRO DE ESTUDOS AGROPECUÁRIOS (CEPEA) DA ESALQ-USP. Boletim do Leite, 2016. Ano 22. n. 254. Jul. Disponível em: < http://cepea.esalq.usp.br/leite/>. Acesso em: 20/07/2016.

CONTADOR, C. R. Avaliação social de projetos. Atlas, 1988.

DEMINICIS, B. B.; VIEIRA, A. L.; KNIFFIS, A. L.; PONCIANO, N. J.; SOUZA, P. M.; BLUME, M. C. Análise econômica de sistemas de produção de leite de cabra no Estado do Rio de Janeiro. Arch. Zootec, v. 57, p. 377-380, 2008.

EMPRESA BRASILEIRA DE PESQUISA AGROPECUÁRIA (EMBRAPA). Sistema de produção de leite (Zona da Mata Atlântica), 2003. Disponível em:

<https://sistemasdeproducao.cnptia.embrapa.br/FontesHTML/Leite/LeiteZonadaMata Atlantica/coeficientes.html>. Acesso em: 20/07/2016.

EMPRESA BRASILEIRA DE PESQUISA AGROPECUÁRIA (EMBRAPA). Raças exóticas, 1994. Disponível em:

<https://www.agencia.cnptia.embrapa.br/gestor/territorio_sisal/arvore/CONT000fckh7 u3u02wx5eo0a2ndxy5j0paq4.html s. Acesso em: 21/07/2016. 


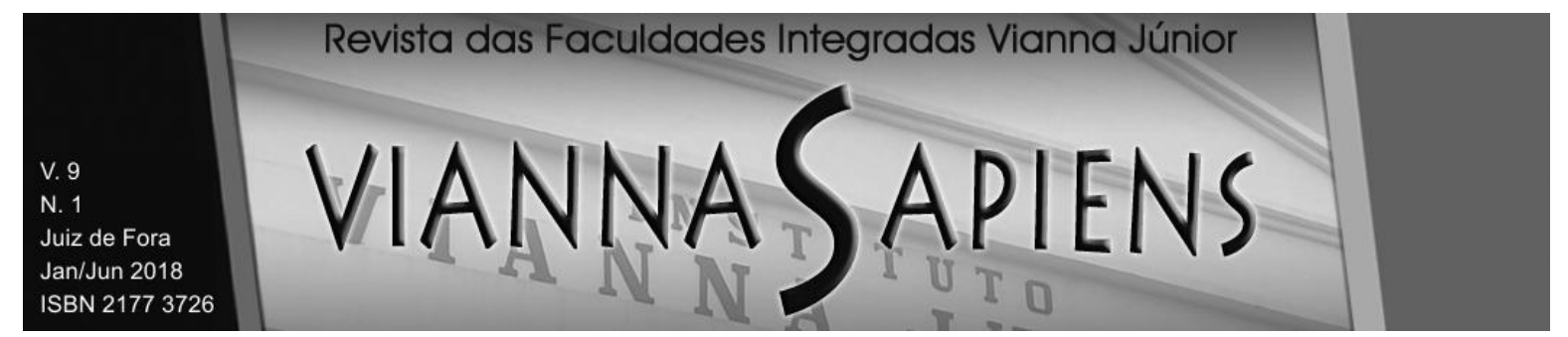

ESPESCHIT, C. J. B. Alternativas para controle da estacionalidade reprodutiva de cabras leiteiras. Encontro Nacional para o Desenvolvimento da Espécie Caprina, v. 5, p. 7-33, 1998.

FAEMG. Mercado e Indicadores - Índice de Preços de Terra, 2016. Disponível em:

<http://www.sistemafaemg.org.br/Conteudo.aspx?Code=69\&Portal=2\&ParentCode= 67\&ParentPath=None\&ContentVersion=R $>$. Acesso em: 25/07/2016.

FARO, C. Elementos de engenharia econômica. Atlas, 1979.

FOOD AND AGRICULTURE ORGANIZATION OF THE UNITED NATIONS (FAO). Statistics of Production, 2016. Disponível em: <http://faostat3.fao.org/search/*/E>. Acesso em: 15/07/2016.

FONSECA, J. F.; BRUSCHI, J. H. A caprinocultura leiteira no Brasil - uma visão histórica. In FONSECA, J.F.; BRUSCHI, J.H. (org.). Produção de caprinos na região da Mata Atlântica. Sobral: Embrapa Caprinos; Juiz de Fora: Embrapa Gado de Leite, 2009.

FONSECA, E. T. D.; OLIVEIRA; C. M. D.; FRANCIOLLI, A. L. R.; MIGLINO, M. A. Características das papilas o dorso da língua de cabras (Capra hircus): estudo por de microscopia eletrônica de varredura e luz. Pesq. Vet. Bras., 31(Supl 1), 67-73, 2011.

GONÇALVES, A. L. Avaliação de sistemas de produção de caprinos leiteiros na Região Sudeste do Brasil. Tese de Doutorado. Universidade Federal de Viçosa, 2005.

GONÇALVES, H. L.; LANA, R. P.; VIEIRA, A. M. Avaliação de sistemas de produção de caprinos leiteiros na Região Sudeste do Brasil. Revista Economia e

Agronegócio, v.37, n.2, 2008.

HAYEK, F. A. Prices and production. Ludwig von Mises Institute, v.107, 1932.

INSTITUTO BRASILEIRO DE GEOGRAFIA E ESTATÍ́STICA (IBGE). Censo Agropecuário de 2006, 2008. 


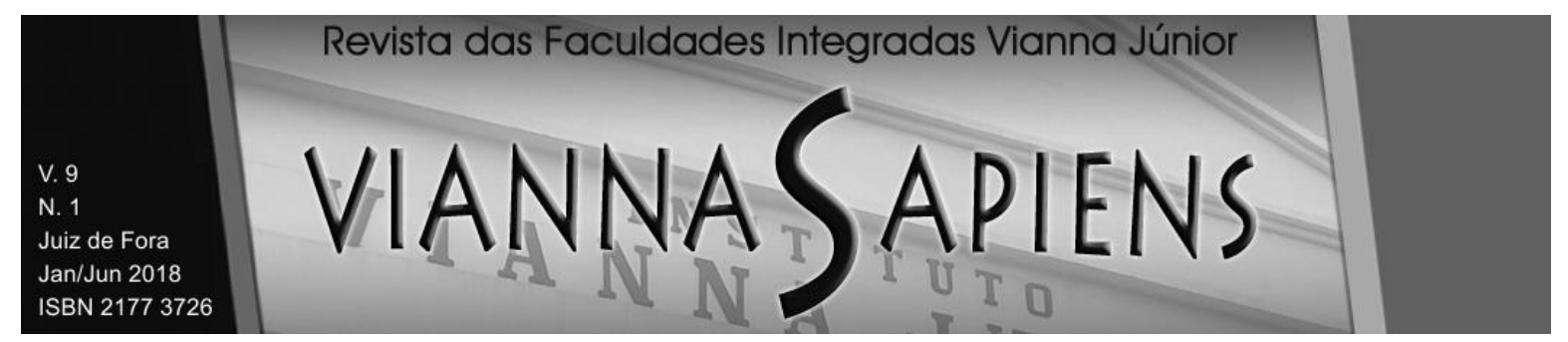

INSTITUTO DE ECONOMIA AGRÍCOLA DE SÃO PAULO (IEA-SP). Preços Médios Pagos pela Agricultura, 2015. Disponível em:

<http://ciagri.iea.sp.gov.br/nia1/Precos_Medios.aspx?cod_sis=5>. Acesso em:

26/07/2016.

INSTITUTO DE PESQUISA ECONÔMICA APLICADA (IPEA). IPEADATA.

Disponível em: <www.ipeadata.gov.br>. Acesso em: 28/07/2016.

KIRIAKOS, V. Onde há incerteza convém minimizar o risco. Gazeta Mercantil. p. 35, set, 1997. (Caderno Mastering Management: O domínio da administração.)

LEAL, G. S. Avaliação Econômico-Financeira de Sistemas de Produção de Leite de Cabra na Zona da Mata Mineira. Trabalho de Conclusão de Curso. Faculdade de Economia e Administração. UFJF, 2010.

LUCAS, R. E. The industrial revolution: Past and future. Lectures on economic growth, 109-188, 2002.

MALHOTRA, N. K. Pesquisa de marketing: uma orientação aplicada. Bookman Editora, 2012.

NORONHA, J. F. Projetos Agropecuários: Administração Financeira, Orçamento e Viabilidade Econômica. 2.ed. Editora Atlas S.A., São Paulo, 269 p, 1987.

PIZARRO, C.; BRESSLAU, S. Custo de produção do leite de cabra. Nova, 22, 972999, 2001.

RESENDE FILHO, M. A.; BRAGA, M. J.; RODRIGUES, R. V. Sistemas de terminação em confinamento: perspectivas para dinamização da cadeia produtiva da carne bovina em Minas Gerais. Revista Brasileira de Economia, v.55, n.1, Rio de Janeiro, jan/mar, 2001.

ROSS, S. A.; WESTERFIELD, R. W.; JORDAN, B. D. Princípios de administração financeira. Atlas, 2008. 


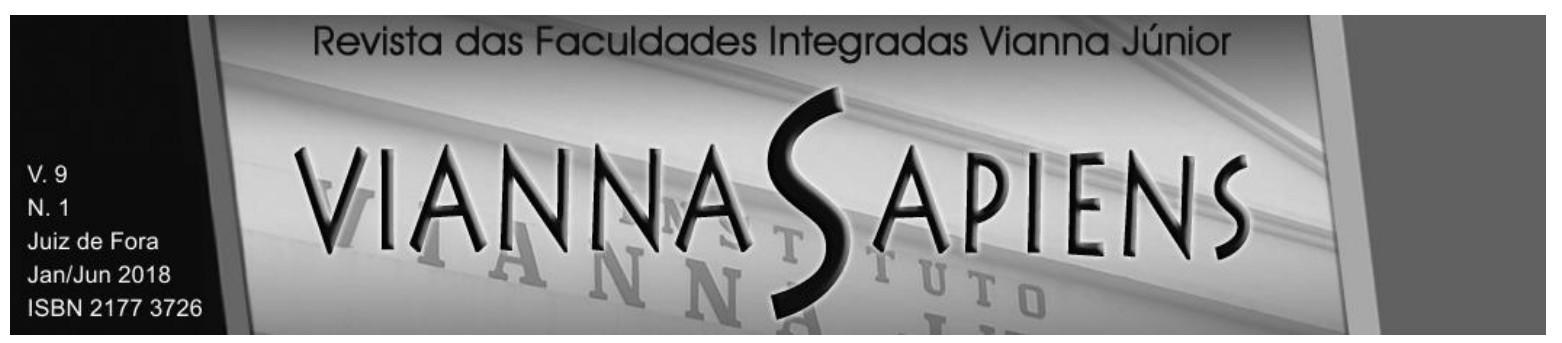

SOARES FILHO, G.; MCMANUS, C.; MARIANTE, A.S. Fatores genéticos e ambientais que influenciam algumas características de reprodução e produção de leite em cabras no Distrito Federal. Revista Brasileira de Zootecnia, 30.v., 133140, 2001.

THOLON, P.; QUEIROZ, S. A.; RIBEIRO, A. C.; RESENDE, K. T.; RIBEIRO, S. D. A. Estudo genético quantitativo da produção de leite em caprinos da raça

Saanen. Archivos Latinoamericanos Producción Animal, 9(01), 1-5, 2001.

VARIAN, H. R. Microeconomia: princípios básicos. Elsevier Brasil, 2006.

Recebido em 16/03/2018

Publicado em 13/08/2018

i FCO = LAJIRD (Lucro Antes dos Juros, Imposto de Renda e Depreciação) - IR (Imposto de Renda).

ii $\triangle K C L=\triangle K C L$ final $-\Delta K C$ Linicial 